Instructions for authors, subscriptions and further details:

http://brac.hipatiapress.com

\title{
Sentido y Responsabilidad: Una Perspectiva Bioética sobre la Creación, Mutación e Hibridación Experimental en el Campo Interdisciplinar de la Tecnociencia y el Arte
}

Laura Baigorri ${ }^{1}$

1) Universidad de Barcelona. España

Date of publication: June $3^{\text {rd }}, 2014$

Edition period: February 2014-June 2014

To cite this article: Baigorri, L. (2014). Sentido y responsabilidad: Una perspectiva bioética sobre la creación, mutación e hibridación experimental en el campo interdisciplinar de la tecnociencia y el arte. Barcelona, Research, Art, Creation, 2(2), 137-168. doi: 10.4471/brac.2014.07

To link this article: http://dx.doi.org/10.4471/brac.2014.07

\section{PLEASE SCROLL DOWN FOR ARTICLE}

The terms and conditions of use, except where otherwise noted, are related to the Open Journal System and to Creative Commons Attribution License (CCBY). The indication must be expressly stated when necessary. 
BRAC - Barcelona Research Art Creation. Vol. 2 No. 2, June 2014, pp. 137-168

\title{
Sense and Responsibility: A Bioethical Perspective on Experimental Creation, Mutation and Hybridization in the Interdisciplinary Field of Technoscience and Art
}

Laura Baigorri

University of Barcelona

(Received: 5 September 2013; Accepted: 10 March 2014; Published: 3 June 2014)

\begin{abstract}
Only humans have created a technoscience able to delete our own kind, and all others, from the face of the earth and if, as affirm the philosopher Hans Jonas, the responsibility is a correlate of the power, the magnitude of power must determine the magnitude of the responsibility. In the last decade, many artists have begun to work in the border areas of science and technology considering the need for a critical analysis in this field developed from extra-medical or extra-industrials criteria. This article examines the works of artists, made under bioart parameters, that impact particularly in the ethical sense of human behaviour toward animals and living things in general. Most projects have been developed in scientific laboratories and have to do with the creation (generation of life), genetic mutation and hybridization, and the symbiotic relationships between animals and humans. Through them, the artists demonstrate their sense of responsibility and their ability to assume the consequences of their creations with the aim to open new ethical debates about science.
\end{abstract}

Keywords: Bioethics, bioart, transgenic art, genetic mutation and hybridization, relationship human/animal. 
BRAC - Barcelona Research Art Creation. Vol. 2 No. 2, June 2014, pp. 137-168

\title{
Sentido y Responsabilidad: Una Perspectiva Bioética sobre la Creación, Mutación e Hibridación Experimental en el Campo Interdisciplinar de la Tecnociencia y el Arte
}

\author{
Laura Baigorri \\ Universidad de Barcelona
}

(Recibido: 5 Septiembre 2013; Aceptado: 10 Marzo 2014; Publicado: 3 Junio 2014)

\section{Resumen}

Sólo los humanos hemos creado una tecnociencia capaz de borrar a nuestra propia especie, y a todas las demás, de la faz de la Tierra y si, como afirma el filósofo Hans Jonas, la responsabilidad es un correlato del poder, la magnitud del poder debe determinar la magnitud de la responsabilidad. En la última década, numerosos artistas han comenzado a trabajar en las zonas fronterizas de la ciencia y la tecnología planteando la necesidad de un análisis crítico en este campo desarrollado a partir de criterios extra-médicos o extra-industriales. Este texto analiza trabajos de artistas, realizados bajo los parámetros del bioarte, que inciden particularmente en el sentido ético de la conducta humana hacia los animales y los seres vivos en general. La mayoría de proyectos han sido desarrollados en laboratorios científicos y tienen que ver con la creación (generación de vida), la mutación e hibridación genética, y con las simbióticas relaciones entre animales e humanos. A través de ellos, los artistas demuestran su sentido de la responsabilidad y su capacidad para asumir las consecuencias de sus creaciones con el objetivo abrir nuevos debates éticos sobre la ciencia.

Palabras clave: Bioética, bioarte, arte transgénico, mutación e hibridación genética, relaciones animal/humano.

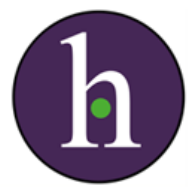


Responsabilidad es el cuidado, reconocido como deber, por otro ser, cuidado que, dada la amenaza de su vulnerabilidad, se convierte en “preocupación”. (Jonas, 1979)

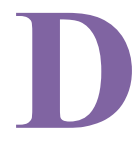

\section{el poder y la ética: el ser humano creador y dominador de la} naturaleza. La condición humana está indisolublemente ligada a la consciencia y la responsabilidad. Somos responsables de nosotros mismos, de nuestros hijos, de nuestra especie y del resto de especies que habitan el ecosistema. Sólo los humanos hemos creado una tecnociencia capaz de borrar a nuestra propia especie y a todas las demás de la faz de la Tierra y si, como afirma el filósofo Hans Jonas, la responsabilidad es un correlato del poder, la magnitud del poder determina la magnitud de la responsabilidad. Los humanos poseemos y gestionamos el mundo y, por lo tanto, somos los máximos garantes de su bienestar y destino. Por supuesto, sufrimos amnesia intermitente.

Las relaciones entre humanos y animales distan mucho de aproximarse a las relaciones de biopoder -ese término acuñado por Foucault para referirse a las prácticas de control de la población por parte de los estados- pues, antes que en el poder, se basan en la dominación absoluta de los primeros hacia los segundos.

Una relación de poder se articula sobre dos elementos que son indispensables para ser precisamente una relación de poder: que "el otro" (aquél sobre el que se ejerce la relación) sea reconocido y mantenido hasta el final como sujeto de acción; y que se abra, ante la relación de poder, todo un campo de respuestas, reacciones, efectos, invenciones posibles. (Foucault, 1984)

La relación entre amo y esclavo es una relación de poder porque existe la posibilidad de huida pero, en su interacción con los humanos, los animales no tienen posibilidad de transformar su situación, están atrapados en una relación asimétrica e irreversible que depende exclusivamente de la ética de sus dominadores.

En el capítulo primero del Génesis, Dios concedía al hombre el control 
y dominio sobre todos los animales y éste no ha dudado en utilizarlos en su beneficio a lo largo de los siglos: para comer, para trabajar, para protegerse, para divertirse, para sentirse acompañado, para experimentar médicamente.... Desde nuestra visión antropocéntrica dominante somos la medida de todas las cosas y nuestros intereses se encuentran por encima de todo lo demás. No obstante, poder y dominio implican responsabilidad; entonces, ¿cuáles son los límites de nuestra responsabilidad?, o expresado de forma aristotélica, ¿debemos hacer todo aquello que podemos hacer? Esta es una de las principales preguntas que plantean los artistas que trabajan en las fronteras de la tecnociencia y el arte.

Haciendo uso del poder absoluto otorgado por Dios -y amplificado después si cabe por la tecnología y la ciencia-, el artista Eduardo Kac “jugó a ser dios" en la obra Genesis (1999). El proyecto consistió en crear un gen sintético que no existía en la naturaleza y para ello insertó dentro de una bacteria un fragmento de $\mathrm{ADN}$ cuya secuencia es precisamente una traducción del pasaje de la Biblia donde Dios concede al hombre el control sobre la naturaleza: "Let man have dominion over the fish of the sea, and over the fowl of the air, and over everything that moves upon the earth" (Génesis, 1.26 28). El gen se creó traduciendo esta frase en código Morse y convirtiendo el código en una base de pares de ADN siguiendo un principio de conversión específico para este trabajo. La obra se presentó como una instalación con conexión online en el Centro Ars Electronica de Linz, de manera que, cuando los participantes remotos se conectaban al proyecto, encendían una luz ultra violeta y la bacteria contenida en una caja de Petri respondía emitiendo una luz visible (cian y amarilla). Con Genesis, Kac estaba "explorando la intrincada relación entre la biología, religión, la tecnología de la información, la interacción dialógica, ética e Internet", pero también proponía una paradoja genial: la nueva obra de materia viva se había creado a partir de las palabras concretas de Dios dándole poder al hombre sobre todos los seres vivos del planeta y aludiendo, a su vez, a la frase de los evangelios: "Y la Palabra se hizo carne y habitó entre nosotros" (Juan 1,14). 


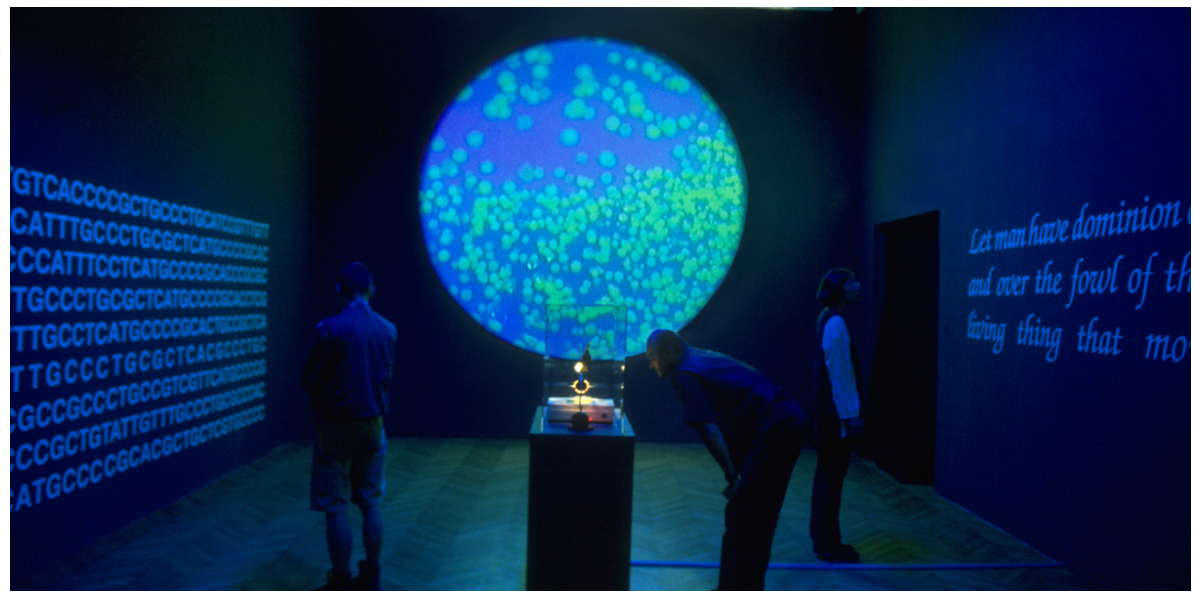

Figura 1. Eduardo Kac, Genesis, 1999. Obra transgénica con bacterias creadas por el artista, luz ultravioleta, internet, vídeo (detalle), edición de 2, dimensiones variables. Colección Instituto Valenciano de Arte Moderno (IVAM), Valencia, España. Foto: Otto Saxinger. Cortesía del artista. (C)

En 1997, Kac acuñó el término de Bioarte para referirse a una práctica artística donde los seres humanos trabajan con tejidos, bacterias y organismos vivos utilizando procesos científicos como la biotecnología. Y en 1998 proponía el concepto de arte transgénico, definido como "una nueva forma de arte basada en el uso de las técnicas de ingeniería genética para transferir material de una especie a otra, o de crear unos singulares organismos vivientes con genes sintéticos". Pero de inmediato lo vinculaba al ejercicio de la responsabilidad:

La naturaleza de este nuevo arte no sólo es definida por el nacimiento y el crecimiento de una nueva planta o un nuevo animal sino, sobre todo, por la naturaleza de relación entre el artista, el público y el organismo transgénico. (...) No hay arte transgénico sin un compromiso firme y la aceptación de la responsabilidad por la nueva forma de vida creada así. Las preocupaciones éticas son de capital importancia en cualquier obra artística y se hacen todavía más cruciales que nunca en el contexto del arte biológico, donde un ser vivo real es la propia obra de arte. (Kac, 1998)

Desde finales de los 90, Kac plantea su trabajo como reflexiones que imprimen un giro ético y estético a los axiomas conocidos; por esta razón, 


\title{
142 Baigorri-Sentido y Responsabilidad: una perspectiva bioética
}

se podría decir que, antes que un simple artista, Eduardo Kac es un filósofopoeta que utiliza el arte para expresar sus pensamientos e ideas.

Unos años antes, entre las obras pioneras del arte de Internet, ya habían aparecido las primeras tentativas de creación y manipulación de vida vinculadas al ejercicio de la responsabilidad, tanto con vida vegetal -Ken Goldberg y The Telegarden (1995-2004)-, como con vida animal -Netband y The Egg of Internet (1995)-. La primera experiencia permitía a los usuarios de la red cultivar su propio jardín a distancia y fue muy popular durante casi una década. El segundo proyecto, sin embargo, fue una obra inconclusa que surgió en Desk.nl ese mismo año; su promotor fue el artista austríaco afincado en Ámsterdam, Franz Feigl, quien reunió a varios artistas e intelectuales interesados en el proyecto bajo el nombre de Netband. Como parte de Desk. nl, el artista Mariano Maturana estuvo colaborando en la construcción de una incubadora provista de una cámara de vídeo que podía registrar en directo el proceso de crecimiento del huevo y explica así cuales eran las premisas de este experimento:

\begin{abstract}
A través de una interface incrustada en el navegador Netscape, los usuarios se podían registrar para tener acceso a la imagen de la cámara en directo, pero al mismo tiempo, sin saberlo, interactuaban con la incubadora generando el calor suficiente para hacer posible que el huevo comenzara su proceso de vida. De esta manera, a mayor cantidad de visitantes, mayor era la cantidad de calor que aseguraba este proceso. Una vez nacido el pollito era necesario alimentarlo y esta actividad era responsabilidad de los usuarios mismos que debían volver al sitio web para interactuar con un sistema que le daba de comer y de beber. La vida del pollito dependía entonces de los usuarios que le habían dado vida. (Entrevista personal en agosto de 2013)
\end{abstract}

En 2011, la artista argentina Marina Zerbarini iniciaba un proceso similar con su obra Síntesis simbiótica entre una máquina y un ser vivo (2011-2013). El 29 de enero de ese año colocó en el Espacio Fundación Telefónica de Buenos Aires tres incubadoras artificiales que incorporaban electrónicamente la luz, el calor y la humedad necesarios para la gestación de huevos fértiles, de tal forma que el proceso podía seguirse en Internet a través de una cámara. En una de ellas se realizaba la gestación, en otra el nacimiento y en la última la alimentación de las aves. La principal intención de Zerbarini era destacar un punto de vista opuesto a intereses industriales y comerciales en este tipo de 
actividades, mostrando las posibilidades de la tecnología para cuidar a estos pequeños seres vivos.

En los dos casos los objetivos eran similares: establecer un sistema cooperativo voluntario que dotase de responsabilidad al ser humano para que, a través de la tecnología, fuese capaz de generar, mantener y cuidar la vida animal. Pero los proyectos de las incubadoras no han acabado de funcionar por problemas técnicos: The Egg of Internet, debido al reducido ancho de banda que tenían los servidores de la época, puesto que el tráfico que generaban las interacciones de los usuarios colapsaba los escasos $2 \mathrm{MB}$ que entonces permitía el servicio de telefonía holandesa. Y Síntesis simbiótica entre una máquina y un ser vivo porque, aunque el volumen de tráfico en Internet siempre fue potente y fluido, surgieron problemas de falta de aireación en las incubadoras, siendo definitiva la dificultad de control del sistema durante los fines de semana, cuando el centro estaba cerrado. Las buenas intenciones de la colectividad artística no han podido superar el delicado equilibrio entre genética y técnica que requerían los pollitos en las incubadoras. La vida animal es muy frágil... y los humanos manejamos demasiadas variables cuando operamos como colectivo espontáneo; unas veces es el insuficiente control sobre la tecnología y otras nuestra inconstancia y falta de previsión. Parece ser que los proyectos que implican a seres vivos no se pueden dejar en manos del azaroso destino que pueda determinar un colectivo anónimo porque los humanos todavía no sabemos manejar la responsabilidad compartida. (A finales de 2013, y tras 5 experiencias anteriores fallidas, Zerbarini consiguió que nacieran 24 pollitos en su casa, pero sin intervención de terceros. Una vez controladas la temperatura y humedad necesarias, la artista persiste en su intento colectivo).

\section{Mutación genética y cría selectiva: cuando los artistas se apropian de prácticas ajenas}

Si modificar el ADN de las células o ayudar a nacer a pollitos pudieran ser considerados experimentos de baja intensidad en la escala de la ingeniería genética (aunque no en el territorio del arte), el siguiente paso en complejidad se encuentra en la mutación y cría selectiva de animales cotidianos, tales como mariposas, peces y conejos.

La artista portuguesa Marta de Menezes viene dedicándose durante más de una década a la creación de obras vivas a través de la experimentación 


\section{Baigorri-Sentido y Responsabilidad: una perspectiva bioética}

genética con animales. En Nature? (1999-2000) trabajó junto al biólogo Paul Brakefield con las larvas de mariposas Bicyclus anynana y Heliconius Melpómene para modificar los patrones de sus alas con fines artísticos, consiguiendo inducir, mediante injertos naturales, un nuevo patrón que antes no existía en la naturaleza.

La intervención artística deja los genes de la mariposa sin cambios, de manera que los nuevos patrones no se transmiten modificados a la descendencia de las mariposas; simplemente desaparecen de la naturaleza sin dejar rastro. Estas obras de arte, literalmente, viven y mueren. Son un ejemplo de arte con una esperanza de vida limitada, la vida de una mariposa. (Menezes, 2003)

El interrogante del título hace referencia al desarrollo completamente natural de las alas, pero como paradójico resultado de la intervención humana. Para Menezes, esta obra cuestiona las similitudes y las diferencias entre lo natural y "lo nuevo natural", evidenciando la posibilidad de reinventar la naturaleza a través de la ciencia, pero asumiendo las consecuencias y sin dañar el ecosistema. Ante este tipo de proyectos algunos se preguntarán ¿pero qué derecho tienen los artistas a crear o mutar genéticamente a los seres vivos? A lo cual podríamos responder con otra pregunta irealmente el problema es que sean los artistas quienes lo hacen?, ¿el principal inconveniente es que la manipulación se establezca desde el mundo del arte y/o esté orientado a un supuesto resultado estético? De acuerdo, el utilitarismo es una excusa para muchos, ya que la finalidad de la experimentación científico-médica con animales es curar enfermedades humanas y de la agraria, la industria de la alimentación. Pero a veces olvidamos que existe una milenaria tradición en la cría selectiva de especies animales, una de cuyas principales funciones es el disfrute estético ${ }^{1}$.

En 1998, Eduardo Kac ya había iniciado la prefiguración de uno de sus proyectos más conocidos -y sin duda el más polémico- proponiendo mutar genéticamente un perro "xolo" mexicano (Xoloitzcuintle),... para que después fuese adoptado por su propia familia.

Pero GFP K-9 (1998) nunca se pudo llevar a cabo porque, a pesar de que la manipulación genética de razas caninas sea una práctica habitual, las leyes y protocolos de laboratorio no permiten trabajar con perros para estos fines. Entonces el artista decidió continuar con el proyecto a partir de un animal de laboratorio “autorizado" y así surgió GFP Bunny (2000), una conejita mutada con un gen de ameba que se muestra de color verde fluorescente sólo cuando 
se ilumina con luz azul. Es importante remarcar aquí que esta característica era completamente inocua para el animal y no le comportaba ninguna secuela física, ni a corto ni a largo plazo. Como asegura el artista, el proyecto no fue nunca "la obra de arte de un conejo verde", sino que comprendía la creación de un conejo verde fluorescente, el diálogo público generado por el proyecto y la integración social del conejo; es decir, un work in progress cuyas fases se desplegaban en creación, reflexión y responsabilidad ${ }^{2}$. La obra ha sido objeto de numerosos artículos y ensayos especializados, pero también llenó muchas páginas de diarios de todo el mundo provocando intensas discusiones a nivel popular sobre las patentes de nuevos animales creados en laboratorio y sobre los límites de la ingeniería genética en la industria y el mercado. Para Kac, el uso concreto de la genética en el arte está orientado a provocar una reflexión, desde una perspectiva social y ética, incidiendo en cuestiones relevantes tales como la integración social y doméstica de los animales transgénicos. (Kac, 2010)

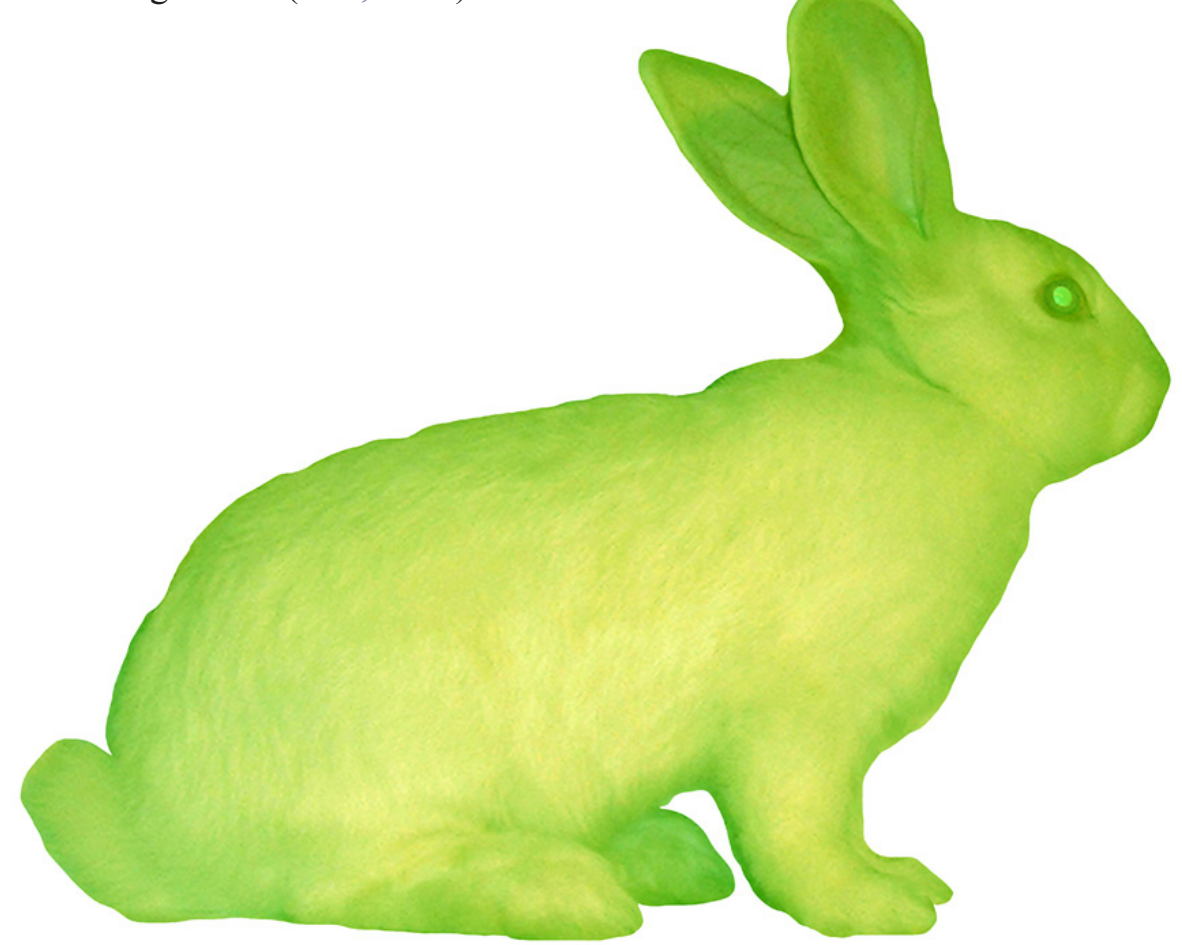

Figura 2. Eduardo Kac, GFP Bunny, 2000. Obra transgénica. Alba, la coneja fluorescente. Cortesía del artista. (C) 


\section{Baigorri-Sentido y Responsabilidad: una perspectiva bioética}

Según Andy Miah (Miah, 2012), las prácticas artísticas que promueven la transgresión de los límites biológicos son más típicas del arte transhumanista, mientras que aquellas obras centradas en el escrutinio de las relaciones biopolíticas son más propias del arte posthumanista. En este sentido, la diferencia crucial entre arte transhumano o posthumano es que el primero se centra en la provocación de debate sobre el mérito de interrumpir la continuidad biológica mediante la ciencia y la tecnología, mientras que el segundo estaría interesado en expresar las consecuencias sociopolíticas de tales cambios. Pues bien, en la base de todos los trabajos de Kac, y en la de la mayoría de los aquí analizados, encontramos las mismas dosis de transhumanismo y posthumanismo enlazadas de forma indisociable, porque cualquiera de las transgresiones biológicas que plantean está orientada a implicar socialmente al público en la reflexión sobre las consecuencias del progreso científico.

En la muestra Project Genesis -inaugurada en agosto de 2013 en el centro Ars Electronica de Linz-, se expone una aséptica obra de la diseñadora alemana Johanna Schmeer que deja a nuestra imaginación las imágenes de los ratones que sugieren sus diseños. Mousetraps No. 3, 14 y 18 (2013) son tres trampas "hechas a medida" para ratones genéticamente modificados en pruebas de laboratorio: la primera, con forma de tubo en espiral, está pensada para el "ratón vals", cuyo trastorno de equilibrio sólo le permite moverse en círculos; la segunda, es un gran imán que atraería con su potente campo magnético el implante cerebral metálico del "ratón ciborg"; la tercera trampa es un altavoz que emite el canto de los pájaros con la finalidad de atrapar al "ratón cantor", desarrollado por investigadores japoneses precisamente para cantar como los pájaros. Los tres ratones descritos no son producto de la desbordante fantasía de Schmeer, sino que han sido creados expresamente en laboratorios. La artista, que argumenta su existencia real con artículos científicos muy concretos ${ }^{3}$, presenta sus diseños bajo una pregunta: ¿Qué sucede si modificamos a las criaturas vivientes y luego las ponemos en libertad? Nuestro cuestionamiento continuaría en la misma línea ¿Es necesario crear a estos seres?, ¿hay alguna utilidad que justifique su sufrimiento y existencia? La modificación genética de Kac en GFP Bunny no producía daños al animal y asumía la responsabilidad y el cariño hacia el nuevo ser creado, pero ¿qué responsabilidad hay en este tipo de creaciones de laboratorio? En la base de este debate se halla una de las obras más recientes de los artistas Revital Cohen y Tuur Van Balen. Kingyo Kingdom (2013) no es un experimento genético, sino un documental que muestra las etapas por las que pasan los peces de colores japoneses de la raza Ranchu para convertirse en preciados objetos; nos encontramos otra vez ante 



Figura 3,4. Revital Cohen y Tuur Van Balen. Kingyo Kingdom (2013). Cortesía de los artistas. (C) 


\section{Baigorri-Sentido y Responsabilidad: una perspectiva bioética}

la enésima demostración del control sobre la naturaleza ejercida por el ser humano. La manipulación del Ranchu, "The King of Goldfish", se inició en el período Edo japonés (1603-1868) en base a dos criterios básicos: un diseño específico para verse siempre desde la parte superior (visión cenital) y que su cabeza sea similar al león mitológico Shishi. Aunque esta exótica raza tiene su origen en la carpa, el objetivo de los criadores es que se parezca lo menos posible ella.

Su vídeo muestra la explicación de los criterios de los criadores, su cultivo en granjas, las fases de su comercio (mercados, subastas y embalajes), los concursos y ceremonias y, en definitiva, el tipo de economía y cultura japonesa que giran en torno a este objeto decorativo vivo. En su web los artistas afirman:

La industria de peces de colores y la cultura japonesa ilustra la existencia única de esta especie; creada por el hombre, biológicamente controlada y diseñada para fines estéticos. A diferencia de muchas otras razas manipuladas, un pez de colores no tiene "función", no se crean como alimentos, mano de obra, tutores o compañeros, sino únicamente como un ser estético.

Su investigación se centra en el diseño de los animales y, más concretamente, en las razones por las que algunos animales se consideran un objeto o un "producto vivo" antes que una mascota. “¿Qué es un bio-producto? -pregunta Cohen- La gente habla de bio-productos como si fueran el futuro, pero ya están por todas partes. Los animales que nos rodean han sido diseñados. Y Ranchu es sólo un caso muy extremo". La perspectiva aparentemente utilitarista de este discurso es el señuelo perfecto de Cohen y Van Balen, cuya estrategia parte del cuestionamiento estético para plantear una posición ética.

\section{Atención, animales trabajando}

Las reflexiones sobre la utilización de los animales han estimulado a algunos artistas a investigar si será posible el desarrollo de trabajo cooperativo entre los seres humanos y otros animales en un entorno tecnocientífico. ¿Pueden los artistas trabajar con los animales como iguales? Este fue el lema de la exposición Insterspecies - artists collaborate with animals (2009), donde el curador Rob la Frenais reunió a un grupo de artistas que cuestionan con sus obras la soberanía de la especie humana sobre las demás especies 
animales. Partiendo de esta pregunta vamos a revisar dos interesantes trabajos colaborativos entre animales y humanos que, aunque no pertenecen a esta muestra, consideramos que comparten plenamente su espíritu.

El primero es Pigeonblog (2006-2008) descrito por su autora, Beatriz da Costa, como un esfuerzo de colaboración entre palomas mensajeras, artistas, ingenieros y criadores de palomas que participaron en la recopilación y distribución de información en una base de datos sobre las condiciones de calidad del aire. Las palomas iban equipadas con un dispositivo en miniatura que medía la contaminación del aire y enviaba la información a un servidor en línea. El proyecto, que se implementó en Los Ángeles por ser una de las zona más contaminadas de EEUU, permitía que los datos enviados por las palomas se representaran muy rápidamente en un mapa desde Google Maps, de manera que cualquier persona conectada podía verlos casi en tiempo real. El propósito de Beatriz da Costa era concienciar sobre la contaminación medioambiental y, a su vez, investigar las posibilidades de coproducción entre especies trabajando en una misma acción de resistencia: “¿Cómo pueden ayudarnos los animales en la sensibilización a la injusticia social? ¿Podría ayudarnos su habilidad para la realización de tareas y actividades que los humanos simplemente no podemos hacer, mientras mantenemos una relación respetuosa con los animales?" (Da Costa, 2008). De esta manera, la artista conseguía unir dos de sus principales intereses vitales en un mismo proyecto: su preocupación por los animales y el entorno medioambiental, y la lucha activista. En Pigeonblog, además, aparecía ese recurrente usufructo de rebote donde una tecnología militar se aprovecha a posteriori por la industria y el comercio,... o por los activistas (una máxima hacker dice que cuando se abre una puerta siempre se puede traspasar en los dos sentidos). Porque la acción de da Costa se había inspirado en una tecnología, desarrollada por Julius Neubronner en 1908, que de inmediato se utilizó para la vigilancia aérea militar en la Primera Guerra Mundial. El invento del ingeniero alemán consistió en colocar alrededor del cuello de las palomas una pequeña cámara con un temporizador mecánico que tomaba fotografías periódicamente mientras éstas sobrevolaban las zonas de interés. La nueva versión de la artista equipaba a las palomas de una forma muy similar y para la misma actividad, las tomas aéreas, pero, por supuesto, con una finalidad completamente distinta.

Revital Cohen y Tuur Van Balen también trabajaron con palomas en su proyecto Pigeon d'Or (2011), pero ahora mismo nos interesa Life Support (2008), una tarea de cooperación entre especies inspirada en la labor de los animales de asistencia (perros-guía, y perros y gatos de asilos y 
servicios psiquiátricos). Este proyecto proponía el uso de animales criados comercialmente para el consumo o el entretenimiento, tales como ovejas y galgos, como proveedores de reemplazo de órganos externos, ofreciendo una alternativa a terapias médicas más duras con los humanos. En Respiratory Dog, la apuesta es que los pacientes dependientes de ventilación mecánica adopten un galgo retirado de las carreras para convertirlo en un perro de asistencia respiratoria. De esta simbiótica manera ambos se pueden mantener vivos el uno al otro.
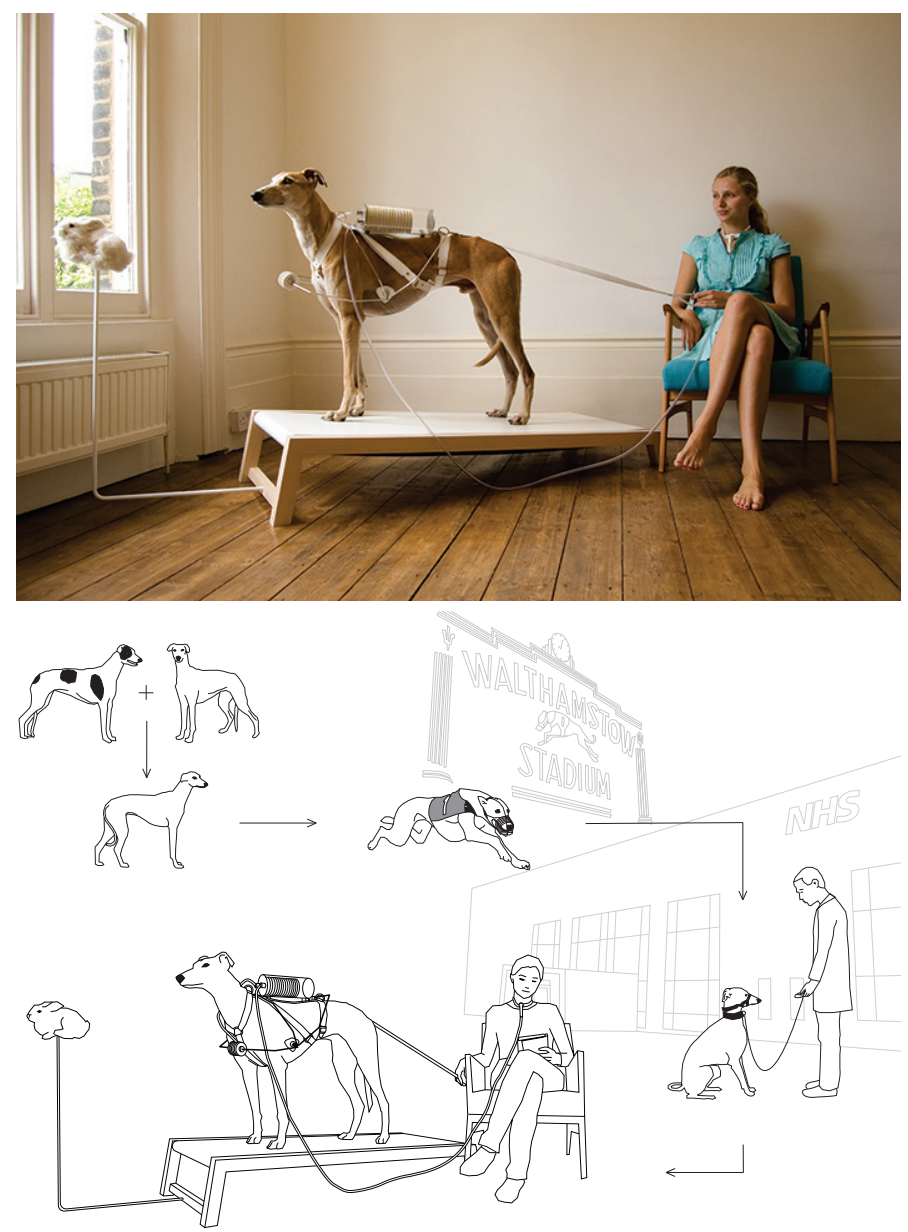

Figure 5. Revital Cohen y Tuur Van Balen. Respiratory Dog, Life Support serie (2008). Cortesía de los artistas. (C) 
Lo mismo sucede con Dialysis Sheep, que contempla la sustitución de una máquina de diálisis por una oveja. Tras posibilitar el nacimiento de un cordero transgénico compatible con el ADN del humano, éste se utilizaría para la diálisis del paciente: durante el día, la oveja se alimentaría normalmente y pasearía por un jardín, y por la noche se conectaría al paciente para filtrar la sangre de sus riñones mientras ambos duermen. En estas relaciones simbióticas, animales, humanos y máquinas coexisten gracias a una estructura compleja que permite la mutua dependencia entre distintas especies. A priori, este controvertido proyecto resulta básicamente utilitarista, puesto que su pretensión más inmediata es transformar a los animales en productos sanitarios. Pero si avanzamos un poco más, constataremos que Cohen y Van Balen inciden de forma especial en la dependencia humana de la animal, demostrando que la necesidad es mutua; de hecho, en la base de su trabajo se encuentra siempre la subversión de los roles de poder entre el hombre y su entorno. "¿Podría funcionar un animal transgénico como un mecanismo conjunto y no simplemente como suministrador de piezas? ¿Podrían los humanos convertirse en parásitos y vivir de las funciones del cuerpo de otro organismo?". En último término, los artistas están cuestionando la instrumentalización de los animales por parte del hombre, porque hace mucho tiempo que los animales son productos sanitarios. $Y$ es que una parte de la investigación científico-médica de los últimos años se centra de forma específica en investigar la compatibilidad de órganos animales -generalmente de cerdos- con los humanos; la técnica biomédica que permite trasplantar corazones, pulmones, riñones, hígados y tejidos de un animal donante clonado a un humano receptor se denomina xenotrasplante.

Retomaremos este tema al final, pero plantearemos ya una cuestión fundamental: partiendo del buen trato hacia al animal, que se cumple en estos últimos proyectos (Pigeon Photogaphy, Pigeonblog y Life Support) ila finalidad de la acción -ganar la guerra, preservar el medioambiente, mejorar la calidad de vida de los enfermos- es determinante en la utilización que los humanos hacemos de los animales?

\section{Máxima empatía e hibridación: colocarse en el lugar del otro (animal)}

¿Qué es lo que puede impulsar a alguien a convivir y dormir junto a un cerdo vivo? ¿Y a bailar con un cerdo muerto? Una máxima empatía, ciertamente. El convencimiento de que ese ser no es alguien muy distinto a uno mismo. Estas 


\section{Baigorri-Sentido y Responsabilidad: una perspectiva bioética}

dos performances las ha realizado de forma literal Kira O'Reilly, una artista irlandesa especialmente preocupada por la ética de la interacción humano/ animal y por la violencia implícita en la utilización de los animales como recurso. O'Reilly habla siempre de "animales humanos" y "animales no humanos" -lo cual ya es una declaración de principios- y para argumentar su postura cita a la artista eslovena Polona Tratnik en su texto Flesh of the World.

Maurice Merleau-Ponty ha creado el concepto de la carne del mundo. Las cosas se pertenecen recíprocamente una a otra y, por lo tanto, forman parte de la misma carne, la carne del mundo. (...) El mundo no existe frente a mí, sino que es todo lo que me rodea, vivo en él y formo parte de él. Lo vivo desde dentro, estoy inmerso. Soy una parte de la carne del mundo donde todo está entrelazado. El mundo está hecho de la misma sustancia, como un cuerpo. (Tratnik, 2006)

Tras una residencia en el laboratorio de SymbioticA, O'Reilly se dio cuenta de las similitudes entre la piel del cerdo y la de los humanos e ideó Inthewrongplaceness (2005), una performance donde bailaba con un cerdo muerto, a la vez que invitaba al público a tocar alternativamente su propia piel y la del cerdo. Porque no sólo los órganos internos de los cerdos son similares a los humanos, sino que el parecido entre nuestras pieles es tal que, en los primeros experimentos con bombas atómicas realizados en los años 50 en el desierto de Nevada (EEUU), los militares norteamericanos colocaban a cerdos (vestidos de uniforme) en los espacios próximos a las explosiones con el objetivo de comprobar cuáles serían los efectos de las radiaciones en la piel humana ${ }^{4}$. En la otra performance, Falling asleep with a pig (2009), la artista exploró los límites de su convivencia con la cerda Deliah al compartir durante unos días una pocilga especialmente construida para ellas en la sala de exposiciones. Allí comieron y durmieron juntas ante un público impresionado por la naturalidad y la ternura de la relación que contemplaban.

En esta misma línea empática de trabajo encontramos las esculturas hiperrealistas de la artista australiana Patricia Piccinini, unas criaturas inquietantes aunque extrañamente familiares, cuya sensación de vulnerabilidad provoca nuestra curiosidad e instinto de protección. En The Long Awaited (2008), una especie de sirénido anciano, mitad humano mitad animal, reposa plácidamente en los brazos de un niño, ambos con los ojos cerrados, serenos y confiados; en Litter (2010) tres bebés de espalda peluda se acurrucan entre ellos dormitando, y en The Listener (2012) un pequeño ser con cuerpo de... 
¿cerdito? y rostro humanoide reposa sobre un enorme altavoz mientras sonríe tímidamente buscando nuestra aceptación. Realizadas con silicona, fibra de vidrio, cabello humano, pelo de animal y ropa -y, en alguna ocasión, con mecanismos y altavoces ocultos en su interior-, las esculturas de Piccinini nos interrogan sobre nuestra responsabilidad para con las criaturas que creamos o las que compartimos la vida. Sabemos que estas son completamente artificiales, pero su apariencia de desprotección y la extraña mezcla de humanidad y animalidad de sus expresiones nos impulsa a preguntarnos ¿qué es lo que sienten estos seres?,... Resulta inevitable mencionar la escena final de La semilla del diablo/Rosemary's Baby (Polanski, 1968), cuando Mia Farrow acuna en sus brazos al anticristo que acaba de dar a luz.

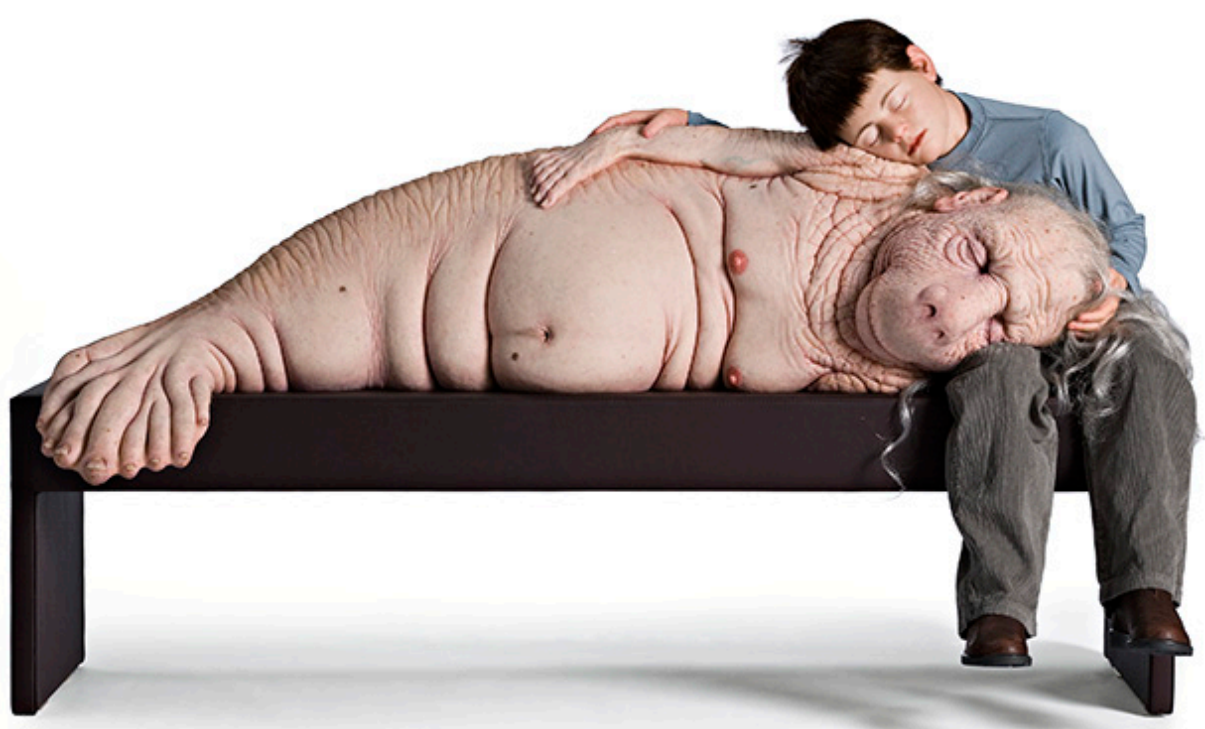

Figure 6. Patricia Piccinini. The Long Awaited, 2008. Silicona, fibra de vidrio, cabello humano, contrachapado, cuero, ropa, 152x80x92cm. Tolarno y Roslyn Oxley9 Galleries. Foto: Graham Baring. (C) 


\section{Baigorri-Sentido y Responsabilidad: una perspectiva bioética}

\section{Viaje de ida y vuelta: Plantúmanos y humanimals}

En el campo de la experimentación biotecnológica, la unión con otro ser alcanza su punto álgido en la hibridación, en la mezcla del ADN de dos seres vivos que da como resultado un nuevo ser que contiene a los dos; estamos ante la generación creativa de vida mediante técnicas de laboratorio. $\mathrm{Y}$ en el territorio del bioarte, estos procesos ya han tenido lugar entre plantas y humanos, e humanos y animales.

En 2009, Eduardo Kac ganó un Premio Golden Nica de Ars Electrónica con su proyecto Historia Natural del Enigma (2009), la creación del plantimal -o plantúmano- "Edunia", que es un híbrido genético entre Eduardo y una petunia. El ADN extraído de la sangre del artista se mezcló con el de la planta para manifestarse en las "venas" también rojas de la flor, compartiendo ambos esta consanguineidad. Además de las consiguientes implicaciones éticas, el proyecto contempla dos ideas singulares: Una es que, como el ADN humano se integra en el cromosoma de la Edunia, cada vez que ésta se propague a través de sus semillas el gen humano estará presente en las nuevas flores propagando de forma natural los genes del artista en las plantas. Y la otra que, haciendo gala de su estilo característico, Kac propone una nueva paradoja para mezclarse con la planta, escogiendo en concreto el gen responsable de la identificación de cuerpos extraños. "Esta secuencia genética que es parte de mi sistema inmune me distingue a mí mismo del no-yo, es decir, me protege contra moléculas extrañas, enfermedades, invasores - todo lo que no soy yo". Esto es, precisamente, lo que le interesa de la propuesta conceptual, que el elemento que condensa su propia defensa y rechazo del otro sea, a su vez, lo que le funde con el otro.

Los filósofos Pitágoras (580-500 a.C.) y Empédocles (495-435 a.C.) creían que animales y humanos poseen el mismo tipo de alma inmortal, de manera que las dos especies podíamos reencarnarnos alternativamente en uno y otro. Y Teofrasto (371-286 a.C.) todavía iba más allá asegurando que los animales son iguales a los humanos, no sólo respecto a su percepción de los sentidos y emociones, sino porque pueden participar en el proceso de razonamiento. Más allá de estas creencias, la afinidad entre humanos y animales alcanza su cota más alta cuando ambos consiguen compartir el mismo cuerpo. Y si en el caso anterior, la especie "invasora" ha sido la humana (una parte de ADN humano inoculado en el organismo de una planta), vamos a ver ahora el proceso de experimentación inverso: cuando parte del ADN de un caballo entra en el cuerpo de un humano. Nos encontramos entonces ante un humanimal. 
Eduardo Kac

The Making of Natural History of The Enigma

Edunia, transgenic flower expressing artist's own DNA in petal veins
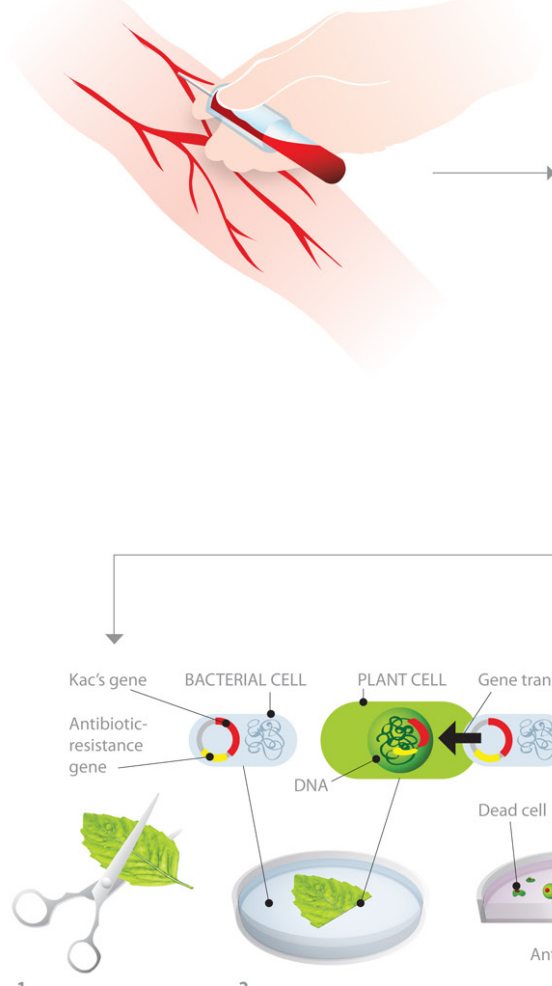

Cut Leaf
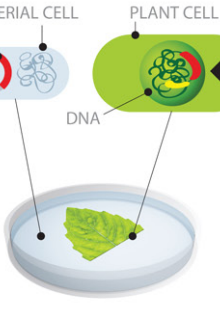

2

Expose leaf to bacteria

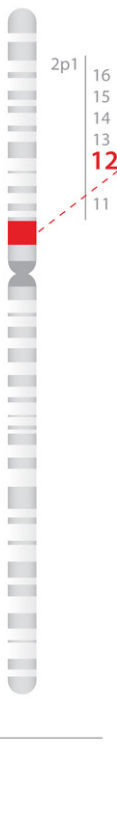

PLANT CELL Gene transfer carrying the new gene and an antibioticresistance gene. Allow bacteria to deliver the genes into leaf cells

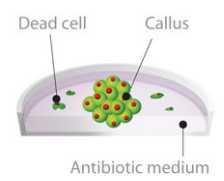

3

Expose leaf to antibiotic to kill cells that lack Kac's genes. Wait for surviving [gene-altered] cells to multiply and form a clump [callus]

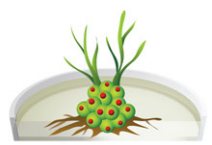

4

Allow callus to sprout shoots and roots
Kac's Chromosome 2

cgaactgtggctgcaccatctgtcttcatct tcccgccatctgatgagcagttgaaatctg gaactgcctctgttgtgtgcctgctgaata acttctatcccagagaggccaaagtacag tggaaggtggataacgccctccaatcgg gtaactcccaggagagtgtcacagagca ggacagcaaggacagcacctacagcctc agcagcaccctgacgctgagcaaagcag actacgagaaacacaaagtctacgcctgc gaagtcacccatcagggcctgagctcg Kac's gene

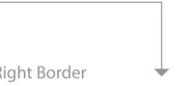

Plant Kanamycin

(1)
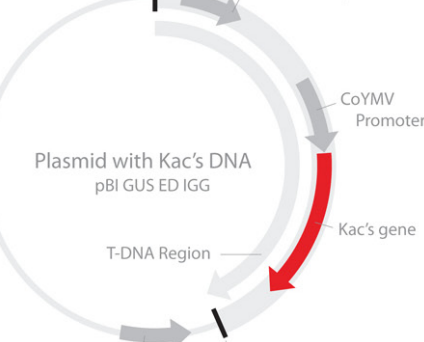

Bacterial Kanamycin

Left Border

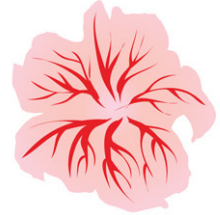

5

Put in soil. Within three months, the plantlets grow into plantimal bearing Kac's gene. The gene is expressed only in the red veins.

Figure 7. Eduardo Kac, Natural History of the Enigma, Obra transgénica, 2003/08. Edunia, un plantimal con el ADN del artista manifestado sólo en las venas rojas de la flor. Diagrama de producción. Cortesía del artista. (C) 


\section{Baigorri-Sentido y Responsabilidad: una perspectiva bioética}

En febrero 2011, Marion Laval-Jeantet y Benoît Mangin, componentes del dúo francés AOO/Art Orienté Objet, culminaron un largo y arriesgado proceso de experimentación en la performance May the horse live in me (2011), que podría describirse como un ritual de hermandad humano-animal donde los artistas asumieron el riesgo de la hibridación orgánica con otra especie. Durante la performance, en la que intervino un hermoso caballo, Benoît Mangin inyectó la sangre del animal a Marion Laval-Jeantet y después ella se colocó unas prótesis, a modo de extremidades equinas, para acercarse al caballo a la altura de sus ojos y completar el rito de comunión. La acción finalizó con la toma de una muestra de la sangre mixta de Marion -"la sangre de un centauro"- que se coaguló a los diez minutos de haberse extraído debido a la infección. El proceso requirió meses de experimentación clínica previa para que ella pudiera desarrollar tolerancia a los anticuerpos de sangre ajena porque, además del choque anafiláctico, la trasfusión de sangre de caballo a un humano comporta muchos más riesgos. Por eso excluyeron algunas células en el proceso (citotóxicos, linfocitos y macrófagos), aunque sí incorporaron la inmunoglobulina, que transfiere información a todos los órganos del cuerpo. Durante la acción en la sala, Marion padeció fiebre y debilidad, pero dos días después se produjeron una serie de reacciones atípicas en su cuerpo: intermitencias rápidas del sueño (era incapaz de dormir más de una hora cada vez), excesivo apetito, una gran sensación de fuerza... y pánico irracional cuando alguien le golpeó el brazo accidentalmente: una serie de síntomas más propios de un equino que de un humano. Durante varios años, Art Orienté Objet se han interesado por la psicología animal, la biología y la etología, pero nunca habían asumido un riesgo tan radical para expresar su protesta contra la dominación humana. Los artistas afirman que este proyecto, que les valió un Premio Golden Nica en la edición de Ars Electronica de 2011, es la consecuencia de un estado de frustración por su incapacidad para colocarse en el lugar de un animal porque, a pesar de sus mejores intenciones éticas, la visión antropocéntrica resulta siempre ineludible. Marion Laval-Jeantet afirma al respecto:

He hecho muchos trabajos sobre los animales -obras de naturaleza simbólica, política y poética-, pero llegó un momento en el que simplemente tenía que experimentar algo distinto de la percepción humana como constante referente. Era necesario para mí demostrar que los conceptos establecidos sobre las barreras entre las especies nos están limitando, e inevitablemente se requiere la investigación científica para 
superarlos. (...) Con el tiempo me di cuenta de que sólo un experimento en mí misma me ayudaría a transformar mi forma de aprender y percibir las cosas, y que con esta nueva sensibilidad sería capaz de crear una nuevo tipo de obras. (Hirszfeld, 2011)

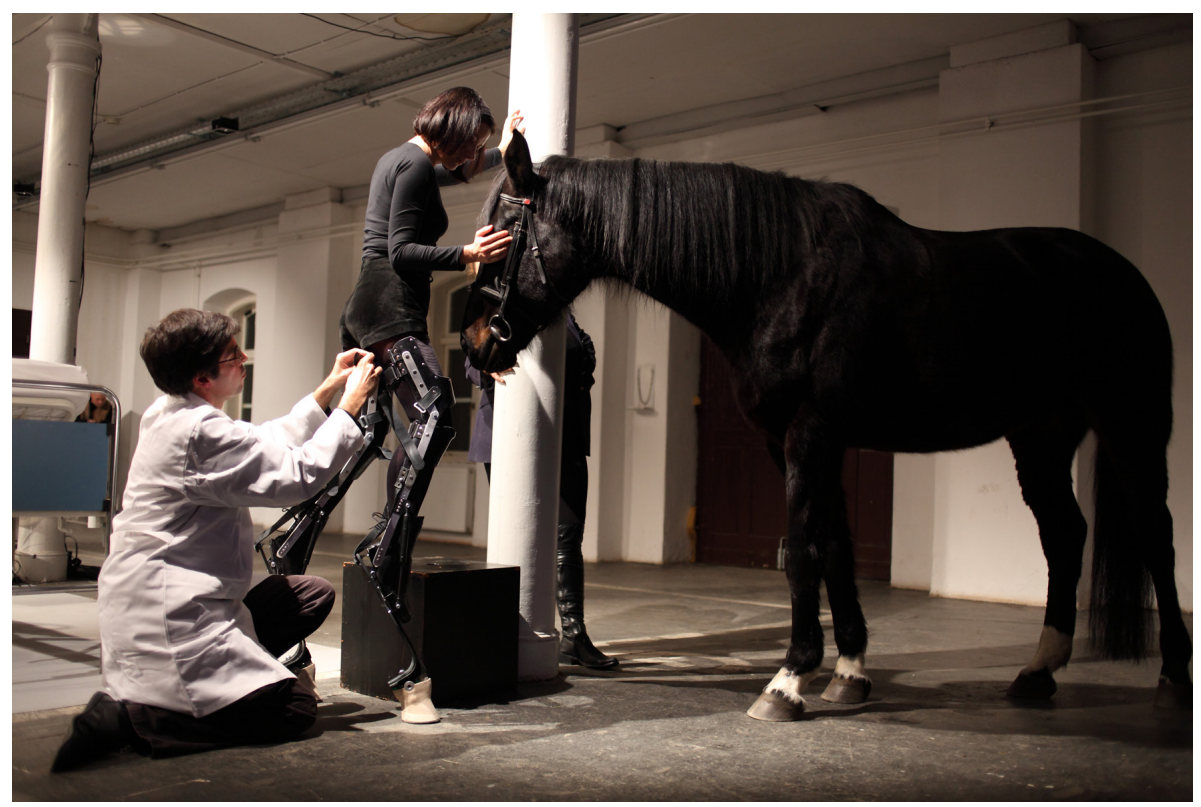

Figure 8. AOO (Art Orienté Objet), May the horse live in me, 2011. Cortesía de los artistas. (C)

Estos proyectos alcanzan su objetivo de empatía extrema porque los artistas se colocan en el lugar del otro a partir de la introducción literal de una parte del otro en su propio cuerpo (o viceversa). Se produce entonces un estallido de los límites entre las especies y comienza el verdadero intento de disolución de control sobre las demás criaturas. Pero más allá de manifiestos y demostraciones explícitas, Donna Haraway nos recuerda que esta fusión de especies se viene produciendo de forma natural en cada ser humano desde el inicio de los tiempos:

Me encanta el hecho de que el genoma humano se encuentre en sólo el $10 \%$ de todas las células que ocupan este espacio mundano que llamo 


\section{Baigorri-Sentido y Responsabilidad: una perspectiva bioética}

mi cuerpo; el otro 90\% de estas células están llenas de genomas de bacterias, hongos, protistas y demás, algunos de los cuales crean la sinfonía necesaria para mantenerme viva y otros se vienen a dar una vuelta en mí, en nosotros, sin dañarnos. Estoy ampliamente superada en número por mis pequeños compañeros, mejor dicho, me convierto en un humano adulto en compañía de estos pequeños seres. Llegar a ser es siempre llegar a ser con muchos. (Haraway, 2008)

En último término, nuestra responsabilidad con la vida en este planeta pasa por procurar la supervivencia conjunta de todas las especies; dicho de otra forma: o somos todos,... o no seremos.

\section{Responsabilidad y asunción de consecuencias: una negociación ética}

Según Hans Jonas, con cuyas palabras iniciábamos este texto, el deber de la responsabilidad humana para con la naturaleza aumenta conforme se tornan más complejos los condicionantes que impone nuestra sociedad tecnológica. Para el filósofo, la responsabilidad deriva de la libertad; sólo los humanos pueden escoger de forma consciente entre diferentes alternativas de acción, pero esa libertad de elección comporta consecuencias (Jonas, 1979). Y si hasta ahora hemos priorizado las intenciones, vamos a centrarnos a partir de aquí en las consecuencias.

Una de las obras más inquietantes que se han podido apreciar en la exposición Project Genesis anteriormente mencionada, es Into Your Hands Are They Delivered (2013), un work in progress del británico Tobias Revell cuyo título ("en tus manos entrego") nos vuelve a conectar con el versículo bíblico del Génesis que comentábamos al principio, cuando Dios otorga a los hombres el dominio sobre los animales. En este caso, la pieza es más narrativa que experimental y consiste en un gran despliegue de datos, textos e imágenes que nos explican una turbadora y apocalíptica historia. El eje y origen del proyecto se encuentra en las Ichneumonidae, unas avispas que ponen sus huevos en los cuerpos de otros insectos, de manera que cuando nacen las larvas devoran a sus anfitriones desde el interior. A partir de aquí, Revell especula sobre una futura evolución de este versátil parásito donde una cepa de la avispa se adaptaría a un proceso de abiogénesis con productos petroquímicos y plásticos; es decir, comenzaría a poner sus huevos en petróleo y gasolina, dejando a las grandes empresas del sector completamente desbordadas por esta gran epidemia con 
alarmantes y definitivas consecuencias, tanto biológicas como financieras.

En esta distópica obra el artista interpela al público: ¿Cómo es posible que estas criaturas, cuyo principio de vida parece tan cruel, sean la creación de un Dios benevolente? ¿Pero acaso somos nosotros, los seres humanos, superiores a los animales? ¿Dónde está la frontera entre la humanidad y la naturaleza? Revell nos invita a hacer una pausa y reflexionar sobre la tipología especulativa del Ichneumonidae y su gran similitud con la actitud de los humanos en nuestro trato habitual al resto de especies y a la naturaleza en general; su propósito es que tomemos conciencia de lo que puede comportar la violación de los límites entre el hombre y la naturaleza.

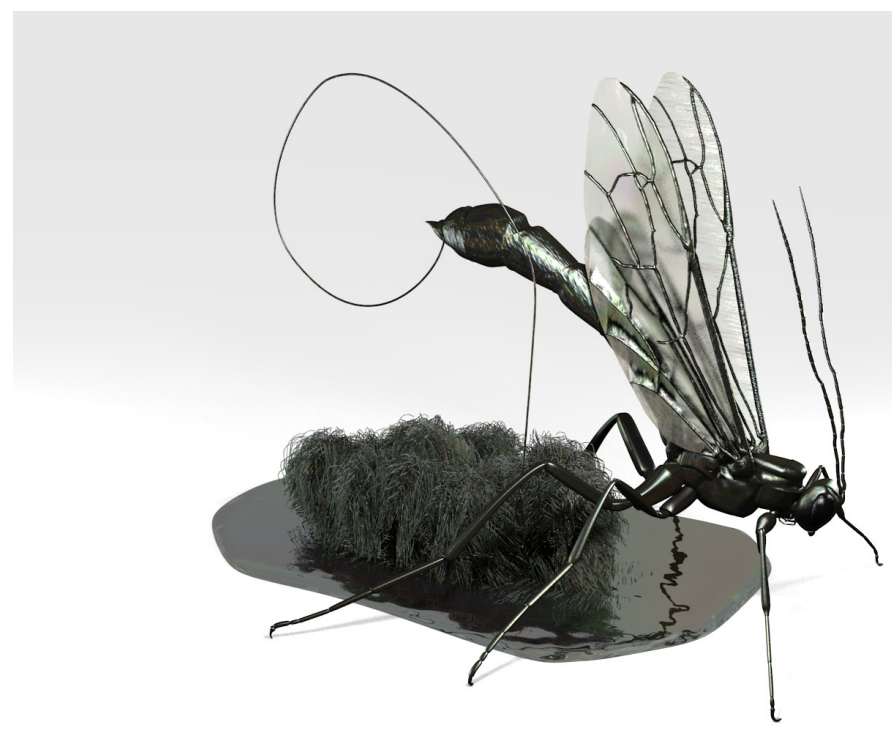

Figure 9. Tobías Revell, Megarhyssa Petrolis hyper-parasitising Larvae, 2013. Cortesía del artista. ()

En este sentido, Revell sigue la estela de Jonas, cuyo imperativo ético parte del miedo o, en sus palabras, de una heurística del temor (Heuristik der Furcht), que significa respeto mezclado con miedo. "Jonas sostiene que es el miedo a las consecuencias irreversibles del progreso, como la manipulación genética y la destrucción del habitat, lo que obliga a actuar imperativamente. Por ello, el motor que impulse a obrar ha de ser la amenaza que pende sobre 
la vida futura". Revell, al igual que Jonas, considera que ante un ultimátum tan definitivo como la amenaza de la existencia (o, en último término, la desaparición de la especie), el hombre debería reaccionar también de manera absoluta:

Ante la amenaza que se cierne sobre la naturaleza, el hombre tiene el deber moral de protegerla, ese deber aumenta en la medida que sabe lo fácil que es destruir la vida; por ello, en la actualidad la ética debe tener en cuenta las condiciones globales de la vida humana y de la misma supervivencia de la especie. La idea fundamental sobre la que se sustenta este planteamiento (de Jonas) es la experiencia de la vulnerabilidad; las generaciones actuales tienen la obligación moral de hacer posible la continuidad de la vida y la supervivencia de las generaciones futuras. (Cardozo, 2003)

Posiblemente, la mayor instrumentalización de los animales por parte de los humanos se lleva a cabo en los laboratorios farmacológicos y médicos de todo el mundo -recordemos de nuevo Mousetraps No. 3, 14 y 18 (2013) de Johanna Schmeer-. Allí es donde se les inocula enfermedades y virus, y donde se experimentan cirugías y medicaciones para comprobar sus efectos. Porque para los humanos, al igual que para las avispas Ichneumonidae, el sacrificio de otras especies comporta la supervivencia de la nuestra. Rabbits Were Used to Prove (1999) de Art Orienté Object muestra el cuerpo disecado de un conejo blanco cuyas entrañas han sido reemplazadas con otras realizadas con lana obtenida de la oveja Dolly, el primer mamífero clonado a partir de una célula somática adulta. Aunque a primera vista pueda parecerlo, la obra no está planteada como una simple crítica a la ciencia o a la utilización de animales de laboratorio, sino que confronta al espectador a la misma encrucijada a la que se enfrentan sus creadores:

La ciencia salva la vida, pero también la sacrifica. Es muy sintomático de nuestra forma de vida en la Tierra -nuestra supervivencia es a costa de los demás-. Este trabajo es más existencial que crítico. En este sentido, me siento cerca de lo que Vladimir Makanin ha escrito. Para nosotros la ciencia no es una posición ideológica, sino un instrumento del que no podemos prescindir si queremos comprender el mundo. Este instrumento, sin embargo, tiene muchas contradicciones internas que pueden ser muy peligrosas para un individuo. Cada vez que utilizamos esta herramienta iniciamos un juego con unos límites de sensibilidad flexibles. (Hirszfeld, 2011) 
Finalizaremos esta reflexión con una obra que alude a la experimentación con las ratas, el animal de laboratorio por excelencia, y donde Beatriz da Costa expone, de forma audaz y en primera persona, las contradicciones humanas. Dying for the Other (2011) es un tríptico de vídeo que yuxtapone las vidas de los ratones utilizados en la investigación del cáncer de mama y la de un ser humano que padece la misma enfermedad, en este caso, la propia autora. Beatriz da Costa documentó el proceso de su enfermedad cancerígena durante los tres meses del verano de 2011 a la vez que grababa, en un laboratorio de Nueva York, a un grupo de ratones a los que se les había inoculado el cáncer:

En este proyecto no intento subrayar ninguna diferencia entre la vida humana y la de un ratón, sino más bien la interconexión que hay entre ambas vidas -aseguraba la artista en una entrevista-. Los ratones son "un animal modelo" usado para desarrollar soluciones para el tratamiento de cáncer de mama. En consecuencia, muchos de ellos tienen que sufrir y morir en un intento de mantener a las personas vivas. En el vídeo exploro el sufrimiento de los dos: ratones y seres humanos. (Lieja Quintana, 2011)

La obra forma parte de un proyecto más amplio titulado The Cost of Life que cuestiona cómo producimos y sostenemos una vida desde diferentes perspectivas -la ética, la emocional y la económica-, evidenciando la complejidad de una práctica que va más allá de mantener un tipo de vida a costa de matar a otro. Beatriz da Costa trabaja en la misma línea que la artista Patricia Piccinini, cuando afirma:

No creo que realmente se pueda -o se deba- tratar de entender la ética sobre algo sin las emociones. Se puede argumentar fácilmente que un enfoque en la empatía podría distraernos de la verdadera comprensión racional de los problemas, pero, de hecho, eso es exactamente lo que yo pretendo. El carácter empático de mi trabajo complica deliberadamente las ideas. Una cosa es argumentar a favor o en contra de la clonación cuando sólo es una cuestión intelectual. Sin embargo, las cosas cambian si tenemos una madre o un hijo que pueda necesitarlo. La ética no se establece de la misma forma que la moral, sino que se debe negociar constantemente. (Piccinini, 2007) 


\section{Baigorri-Sentido y Responsabilidad: una perspectiva bioética}

Así pues, parece que los principales interrogantes de este texto planean en torno a la vieja cuestión maquiavélica sobre si el fin justifica los medios. Y aunque partimos de un claro posicionamiento, nuestras preguntas no esperan una respuesta categórica o concluyente porque ésta no existe. No es a la moral, a quien se dirigen, sino a la ética; y la postura ética personal no se puede fijar para todas las cosas, sino que se adecua a cada situación en particular, es decir, se negocia según las circunstancias específicas de cada realidad concreta. Beatriz da Costa sobrellevó su "realidad concreta" ejemplificando hasta las últimas consecuencias el lema arte $=$ vida. The Cost of Life fue el último proyecto de una persona inteligente y valiente que murió de cáncer el 27 de diciembre de 2012 en Nueva York. Con su vida y su trayectoria artística e intelectual, Beatriz da Costa (1974-2012) ha ayudado a cambiar las ideas y expectativas de otras personas, más allá de su muerte.

\section{Epílogo}

El largo camino de convergencia investigadora entre artistas y científicos se iniciaba en 1959, cuando Lord Charles Pierce Snow (Snow, 1963) declaró la disociación categórica entre ciencias y humanidades en su célebre conferencia The Two Cultures and the Scientific Revolution (Cambridge, 1959). Esta disertación estaba orientada a reflexionar sobre las condiciones de un mundo más justo y sostenible antes que a abordar específicamente la dualidad del arte y ciencia, por lo que posteriormente reconsideró su postura sobre esta división radical y, en 1963, publicó un nuevo ensayo titulado The Two Cultures: A Second Look donde se planteaba el potencial de una Tercera Cultura abierta a la comunicación entre intelectuales literarios y científicos. En 1995, John Brockman asentó las bases de esa Tercera Cultura (Brockman, 1995), proyectando una construcción cooperativa que facilitase una comunicación intercultural más efectiva y creativa; por supuesto, esta es una propuesta todavía en trámites de consolidación. Siguiendo la estela de sus predecesores, Roger Frank Malina dio una conferencia titulada LeonardoTimeshift. 1959, 1969, 2004, 2029 (Ars Electronica 2004), donde argumentaba dos posibles opciones de fusión entre arte, ciencia y tecnología en nuestro futuro inmediato: La opción débil y la opción fuerte. La primera se fundamenta en la interacción entre artistas, científicos e ingenieros para contribuir con resultados mejores y más rápidos a la resolución de problemas científicos o de ingeniería. La opción fuerte, sin embargo, sostiene que en 
unos 20 años surgirán nuevas iniciativas y metodologías de interacción entre artistas, científicos e ingenieros a partir de una ciencia o ingeniería "diferente" porque se habrá producido un cambio sustancial en los contextos sociales e institucionales que hasta ahora definen cuáles son los problemas, qué soluciones son exitosas y en qué áreas se debe priorizar la financiación. A partir de aquí, Malina se atreve a augurar una "Quinta Cultura" que debería implantarse dentro de unos 50 años. En lugar de articular las opciones en oposiciones binarias, considera que será más productivo recuperar la metáfora de la red y ver el arte, la ciencia, la tecnología como una red continúa de "caminos" para comprender y actuar sobre el mundo ${ }^{5}$ (Malina, 2004).

En julio de 2006, el investigador y artista Stephen Wilson escribía en el statement de su web:

Estoy asombrado y preocupado al mismo tiempo por el curso de la investigación científica y tecnológica. Históricamente, las artes vigilaban la frontera cultural, alertaban a la gente sobre los nuevos acontecimientos, examinaban las implicaciones tácitas y exploraban los futuros alternativos. Me temo que en el mundo dominado por la tecnología contemporánea está fallando esa responsabilidad.

Años antes, ya había argumentado las razones por la cuales consideraba fundamental la labor de los artistas en la confluencia del arte, la ciencia y la tecnología: porque partiendo de los mismos datos los artistas pueden introducir nuevas preguntas y asignar diferentes prioridades a una investigación, porque pueden cuestionar los procedimientos de investigación estándar o inventar otros nuevos, porque pueden inventar nuevas tecnologías y nuevas maneras de acceder al conocimiento, porque pueden interpretar los resultados de manera diferente y porque pueden identificar implicaciones culturales de los resultados de investigación que otro tipo de investigadores no tienen en cuenta (Wilson, 2002; Wilson, 2004). La certificación de esta nueva perspectiva queda patente en algunas de las principales preguntas que los artistas analizados han formulado con sus obras:

¿Es necesario crear a determinados seres?, ¿cuál es nuestra responsabilidad hacia las creaciones de laboratorio?, ¿qué sucede si modificamos a las criaturas vivientes y luego las ponemos en libertad?

¿Qué derecho tienen los artistas a crear o mutar genéticamente a los seres vivos?, ¿el principal inconveniente es que la manipulación se 


\section{Baigorri-Sentido y Responsabilidad: una perspectiva bioética}

establezca desde el mundo del arte?, ¿pueden los artistas trabajar con los animales como iguales?

¿Podrían ayudarnos los animales en la realización de tareas que los humanos no podemos hacer, mientras mantenemos una relación respetuosa con ellos?, ¿podría funcionar un animal transgénico como un mecanismo conjunto y no simplemente como suministrador de piezas?, ¿podrían los humanos convertirse en parásitos y vivir de las funciones del cuerpo de otro organismo?

¿Cuáles son los límites de la fusión entre especies?, si fuéramos capaces de crear seres híbridos entre animales y humanos ¿qué percepción tendríamos de su alteridad, en qué rango les ubicaríamos y cual sería nuestra responsabilidad hacia ellos?

En la actualidad, ya no se puede asegurar que la investigación artística sea una actividad marginal en este campo. La justificada preocupación de Wilson está siendo superada por numerosos artistas, conscientemente involucrados en las zonas fronterizas de la ciencia y la tecnología, que asumen el papel de provocadores con el objetivo de implicar socialmente al público en las consecuencias de la innovación y el progreso científico. Históricamente, la responsabilidad de los artistas ha sido propiciar la reflexión y cuestionar los desafíos de su tiempo y si en un momento dado el interés del arte se centró en la crítica social y política, ahora mismo la necesidad de análisis crítico y debate pone también su acento en el territorio de la tecnociencia. Desde distintas perspectivas, todos los proyectos analizados en este texto ilustran los retos que plantean los artistas que trabajan en el bioarte, en su responsabilidad y obligación de abrir nuevos debates éticos sobre la ciencia.

\section{Agradecimientos}

Investigación para el proyecto I+D Metamétodo: Metodologías compartidas y procesos artísticos en la sociedad del conocimiento, 2011-2013, Universidad de Barcelona.

By downloading the images on this link you agree to the following conditions:

The use of these files is strictly limited to this single use: The BRAC Magazine. Any further reproductions, reprints or distribution to third party of these files will be considered a breach of copyright. After the authorized use of these images, the download links and their contents must be deleted. The use of the image files for additional prints - in particular for commercial purposes (catalogues, postcards, posters), without written permission is strictly prohibited. 


\section{BRAC - Barcelona Research Art Creation, 2(2)}

\section{Notas}

1 Las diferencias entre un Gran Danés -hasta $2 \mathrm{~m}$ de altura y de $60 \mathrm{~kg}$ a $100 \mathrm{~kg}$ - y un Yorkshire Terrier -entre 15 y $30 \mathrm{~cm}$ de altura y de 1 ' $5 \mathrm{~kg}$ a $3 \mathrm{~kg}$ - no han sido producto de las azarosas combinaciones de la madre naturaleza. Las consecuencias de esta experimentación son numerosos problemas de salud asociados a sus tamaños; en el Gran Danés: torsión gástrica, displasia de cadera, enfermedades del corazón, tumores y lesiones de la cola; en el Yorkshire Terrier: luxación de la rótula, enfermedades del corazón, hidrocefalia, hipoglucemia y fontanelas abiertas.

2 El último de los tres objetivos de Kac con GFP Bunny -y quizás el más importante- no se cumplió. Aunque la conejita Alba recibió el cariño de la familia de Kac, nunca pudo ser definitivamente adoptada porque las estrictas normativas de los laboratorios impiden que cualquier animal que haya sido intervenido en ellos pueda salir "al exterior". En esta ocasión, fueron las reglas y protocolos científicos los que bloquearon los intereses éticos.

3 "Ratón vals": Stein, K. F., Huber Filosa, S. (1964), "A new mutation causing circling behaviour in mice', Journal of Heredity, Volume 55, Issue 5, pp. 247-252; "Ratón ciborg": Graham-Rowe, D. (2002), 'Robo-rat controlled by brain electrodes',

http://www.newscientist.com/article/dn2237; "Ratón cantor": Agence France Press (2010), 'Singing mouse made with genetic modification'

http://news.discovery.com/animals/zoo-animals/mouse-tweets-genetic-modification-101221.htm (consultados en agosto de 2013)

4 "Se llevaron a cabo experimentos con ratones, perros y otros animales. Los animales se sometieron a las explosiones atómicas y después fueron analizados por biólogos, veterinarios y personal médico. En 1957, para la serie Plumbbob, construyeron corrales cerca de la autopista Mercury para guardar a los 1.200 cerdos que se utilizaron en diversos experimentos. Habían sido especialmente criados para ello, debido a las similitudes entre los cerdos y fisiología humana. En algunos experimentos, se equipó a los cerdos con diversos tipos de ropa, incluyendo uniformes militares. Para la prueba de 37 kilotones del test de Priscilla, realizada el 24 de junio de 1957, colocaron a más de setecientos cerdos anestesiados en estaciones a diferentes distancias de la zona cero con el objetivo de comprender mejor los efectos de las armas atómicas en los seres humanos". Palevsky, Mary (2009), “Atmospheric Nuclear Testing at the Nevada Test Site", marzo. http://www.onlinenevada.org/articles/atmospheric-nuclear-testing-nevada-test-site (consultado en agosto de 2013)

5 Desde su punto de vista, la primera cultura sería la Cultura del Arte, el Diseño y el Entretenimiento interconectadas; la segunda, la Red de la Ciencia, con una mayor dependencia gubernamental; la tercera cultura se centraría en la Tecnología, pero vinculada más estrechamente a la industria; la cuarta cultura estaría formada por un conjunto de culturas ligadas a una serie de "visiones del mundo" dependientes de la ciencia y la tecnología; y la quinta tendría que ver con equipos de colaboración que trabajarían los puntos de encuentro de visiones locales y globales (el idioma, el origen étnico, la pertenencia a una disciplina, grupo social y localidad determinan como se define el interés de los problemas, qué soluciones se consideran exitosas y qué métodos se van a utilizar para averiguar una pregunta en particular). Malina, Roger Frank. LeonardoTimeshift 1959, 1969, 2004, 2029, Ars Electronica 2004.

http://90.146.8.18/en/archives/festival_archive/festival_catalogs/festival_artikel. asp? ProjectID=12927 (consultado en agosto de 2013) 
166 Baigorri-Sentido y Responsabilidad: una perspectiva bioética

\section{Referencias}

Brockman, J., ed. (1996). La Tercera Cultura. Más allá de la revolución cientifica, Metatemas n.43, Barcelona: Tusquets. Primera edición 1995: The Third Culture: Beyond the Scientific Revolution. New York: Simon \& Schuster.

Cardozo, L. (2003). Fundamentos filosóficos para un nuevo discurso ambiental en América Latina. Tesis doctoral, Maracaibo, Venezuela:

Universidad de Zulia. Recuperado en agosto de 2013, de http://tesis.luz.edu.ve/tde busca/arquivo.php? $\operatorname{codArquivo}=2625$

Da Costa, B. (2008, 10 de marzo). Pigeonblog. Interspecies coproduction in the pursuit of resistant action, en MutaMorphosis: Challenging Arts and Sciencies. Actas de la conferencia. Recuperado en agosto de 2013, de http://mutamorphosis.wordpress.com/?s=pigeonblog

Foucault, M. (1984). Deux essais sur le sujet et le pouvoir, en Hubert Dreyfus et Paul Rabinow, Michel Foucault, un parcours philosophique, París: Gallimard.

Haraway, D. (2008). When Species Meet, Minneapolis: University of Minnesota Press.

Hirszfeld, A. (2012), May the Horse Live in me (interview with Art Orienté Objet), en Art+Science Meeting, Gdańsk, Polonia: Laznia Centre for Contemporary Art. Recuperado en agosto de 2013, de http://artandsciencemeeting.pl/?page_id=306\&lang=en

Jonas, H. (1995). El principio de responsabilidad. Ensayo de una ética para la civilización tecnológica, Barcelona: Herder. Primera edición 1979: The Imperative of Responsibility: In Search of Ethics for the Technological Age, Chicago: University of Chicago Press.

Kac, E. (1998). Transgenic Art en Leonardo Electronic Almanac Vol. 6, N. 11. En español en: Molina, A. y Landa, K. eds. (2000). Futuros emergentes: Arte, Interactividad y Nuevos Medios, (pp.59-66) Valencia: Institució Alfons el Magnànim - Diputació de Valencia. (2010). Telepresencia y Bioarte. Interconexión en red de humanos, robots y conejos. Murcia: Cendeac. Primera edición 2005: Telepresence and Bioart. Networking Humans, Rabbits and Robots. Ann Arbor: The University of Michigan Press

Lieja Quintana, D. (2011, Noviembre). "Beatriz da Costa: The Cost of Life". Entrevista en (R)registromx. Literatura, Arte, Pensamiento, n.24. 
Recuperado en agosto de 2013, de

http://registromx.net/anteriores/24/24 bun beatriz.html

Malina, R. (2004). LeonardoTimeshift 1959, 1969, 2004, 2029, conferencia

en Ars Electronica 2004. Linz. Recuperado en agosto de 2013, de http://90.146.8.18/en/archives/festival_archive/festival_catalogs/ festival artikel.asp?iProjectID $=12927$

Menezes, M. (2003). The Artificial-Natural: Manipulating butterfly wing patterns for artistic purposes, en Leonardo Vol. 36: 29-32, Cambridge: MIT Press. DOI: 10.1162/002409403321152257

Miah, A. (2012), "Bioarte: actuación transhumana y posthumana", en Teknokultura Vol. 9 Núm. 1: 85-104. Madrid. Recuperado en febrero de 2014, de http://teknokultura.net/index.php/tk/article/view/53/pdf

Piccini, P. \& Fernández Orgaz, L. (2007). The Naturally Artificial World. En el catálogo de la exposición (tiernas) criaturas, Artium, Vitoria-Gasteiz. Snow, C. P. (1987). Las dos culturas y un segundo enfoque. Madrid: Alianza Editorial. Primera edición (1963): The Two Cultures: and A Second Look. Cambridge: Cambridge University Press.

Tratnik, P. (2006). "Flesh of the World" en a minima n. 18, Barcelona.

Recuperado en agosto de 2013, de

http://www.polona-tratnik.si/Tratnik_Flesh_of_the_World_Aminima.pdf Wilson, S. (2002). Information Arts: Intersections of Art, Science, and

Technology, Cambridge: MIT Press/Leonardo.

(2004). Potential Contributions of Artists to Biology Research, en

Poissnat, L. y Daubner, E. eds. Art et Biotechnologies, Montreal:

Presses de l'Universite du Quebec. Recuperado en agosto de 2013, de http://userwww.sfsu.edu/swilson/papers/wilson.bioartschapter.html

\section{Obras}

Eduardo Kac: Genesis (1999), GFP Bunny (2000) y Natural History of the Enigma (2009) http://www.ekac.org

Ken Goldberg: The Telegarden (1995-2004)

http://queue.ieor.berkeley.edu/ goldberg/garden/Ars/

Net-Band: The Egg of Internet (1995)

http://v2.nl/archive/works/the-egg-of-the-internet

Marina Zerbarini: Síntesis simbiótica entre una máquina y un ser vivo (2011- 
168 Baigorri-Sentido y Responsabilidad: una perspectiva bioética

2013) http://www.marina-zerbarini.com.ar/simbiosis/index.html Beatriz da Costa: Pigeonblog (2006-2008) y Dying for the Other (2011) Cohen Van Balen: Life Support (2008) y Kingyo Kingdom (2013)

http://www.cohenvanbalen.com

Marta de Menezes: Nature? (1999-2000) http://martademenezes.com/

Johanna Schmeer: Mousetraps No. 3, 14 y 18 (2013)

http://www.johannaschmeer.com/MOUSETRAPS-NO-3-14-18

Kira O’Reilly: inthewrongplaceness (2005)

http://www.artsurgery.org/Tract\%20live\%20art/Kira\%200\%27Reilly/

Kira\%200\%27Reilly.html

Patricia Piccinini: The Long Awaited (2008), Litter (2010) y The Listener (2012) http://www.patriciapiccinini.net/

AOO/Art Orienté Objet: May the horse live in me (2011) y Rabbits Were Used to Prove (1999) http://aoo.free.fr/

Tobias Revell: Into Your Hands Are They Delivered (2013)

http://into-your-hands.com/

Laura Baigorri: Profesora Titular en el Departamento de Diseño e Imagen de la Universidad de Barcelona.

Contact Address: Facultad de Bellas Artes. Universidad de Barcelona. Departamento de Diseño e Imagen. c/ Pau Gargallo 4, 08028 Barcelona (España).

E-mail address: lbaigorri@ub.edu 